\title{
An empirical investigation to use solar-geothermal hybrid energy system for small towns
}

\author{
Sara Orougi ${ }^{a^{*}}$, Ali Esmailzade Maghari ${ }^{b}$, Hoshang Mohammadic, Amir Mansour Gol Mohammadic and \\ Momammad Iranic
}

${ }^{a}$ Department of Management and Accounting, Islamshahr Branch, Islamic Azad University (IAU), Tehran, Iran

${ }^{b}$ Department of Management and Accounting, Science and Research Branch, Islamic Azad University (IAU), Tehran, Iran

${ }^{c}$ National Iranian Gas Distribution Company, Qom Branch, Qom, Iran

\section{A R T I C L E I N F O \\ A B S T R A C T}

\section{Article history:}

Received April 28, 2012

Received in Revised form

July, 29, 2012

Accepted 10 August 2012

Available online

16 August 2012

Keywords:

TOPSIS

Ranking

Internal rate of return

Geothermal energy
During the past few years, there has been increasing interest to find a replacement for gas consumption in Iranian small towns and cities. The government believes delivering cheap gas to small towns is not economical and can be replaced with recent technological solar-geothermal hybrid energy system. In this paper, we present an empirical study to calculate internal rate of return (IRR) for a small town located near the city of Qom, Iran. We consider three scenarios of population, namely 1000, 1500 and 2000 households and various rates for gas price from 7 to 40 cents. The results show that a gas distribution unit yields $2 \%$ to $20 \%$ in terms of return. This brings us to conclude that gas distribution for small towns far from major cities is not economically justified for government. Therefore, we need to use alternative methods such as solar-geothermal hybrid energy system. We use TOPSIS method, as a multi criteria decision making approach, to prioritize ten small towns in Qom province and the results are analyzed.

\section{Introduction}

The recent jump in oil prices have warned many to look for alternative replacement energies such as solar energy, geothermal or a hybrid of both. Recent advances in technology has reduced the cost of environment friendly energy replacement and has created tremendous opportunities for different occasions such as small towns located away from major gas pipelines or cities located in mountains where it costs significant amount of investment for gas distribution infrastructure. During the past few years, there have been tremendous efforts on investigating different opportunities for the replacement of gas as a source of energy. Geothermal energy for electricity generation has been built commercially since 1913, and for many years on the scale of hundreds of mega watt (MW) both for electricity generation and direct use. The utilization has increased during the last four decades. In

\footnotetext{
* Corresponding author. Tel: +989358706494 E-mail addresses: s_orougi@yahoo.com (S. Orougi) 
2000, geothermal resources were identified in over 80 different countries and there were quantified records of geothermal utilization in 58 countries in the world (Fridleifsson, 2001).

Astolfi et al. (2011) presented a combined concentrating solar power system and a geothermal binary plant based on an Organic Rankine Cycle (ORC) where a supercritical ORC, designed for the optimal utilization of an intermediate enthalpy geothermal source. They also used a solar parabolic trough field in the plant, introducing an additional high temperature heat source for the cycle and increasing power production. Imroz Sohel et al. (2011) investigated Geothermal power in New Zealand's as a renewable electricity supply. They reported that modular type binary cycle plants had been imported and installed in different geothermal fields in the country, with plans for further expansion.

Kaygusuz and Kaygusuz (2004) performed an investigation in Turkey and explained that this country was an energy importing nation with more than half of required energy requirements were met by imported fuels, which resulted air pollution in the country. Therfore, they sugges using geothermal energy as attractive solution for clean and sustainable energy future for Turkey. They explained that Turkey is the seventh richest country in the world in geothermal energy potential and the main uses of geothermal energy include space heating and domestic hot water supply, greenhouse heating, etc. They reported that present applications of geothermal energy could be a good clean and much cheaper compared to the other fossil and renewable energy sources for Turkey.

Kose (2007) presented geothermal energy potential for power generation in Turkey in a case study in Simav, Kutahya and reported similar advatantages of using this kind of energy. Nannen et al. (1976) performed an investigation of the technical and economical feasibility of using low temperature geothermal sources in Colorado. Murphy and Niitsuma (1999) discussed strategies for compensating for higher costs of geothermal electricity with environmental benefits. Rodríguez and Díaz (2009) analyzed the utilization of mine galleries as geothermal heat exchangers by means a semi-empirical prediction method. Thomaidis et al. (2008) studied the wholesale natural gas market prospects in the energy community treaty countries. Vélez et al. (2012) presented technical, economical and market review of organic Rankine cycles for the conversion of low-grade heat for power generation. Yildirim Ozcan and Gokcen (2009) performed an investigation on thermodynamic assessment of gas removal systems for single-flash geothermal power plants.

As we can see from this literature, there are some benefits of using new sources of energy but the problem is where we should we start using such projects. To answer this question we must consider different criteria such as the availability of sun light, temperature, etc. In other words, this is more a multi criteria decision making problem. During the past few decades, there have been significant attempts on having efficient methods proposed for ranking different alternatives such as data envelopment analysis (DEA) (Charnes et al., 1978, 1994; Andersen et al., 1993), analytical hierarchy process (AHP) (Saaty, 1992), Entropy and Technique for Order Preference by Similarity to Ideal Solution (TOPSIS). Some of the techniques asks decision maker (DM) to give his/her opinions for ranking preference, for instance AHP, while the others do not, e.g. DEA. In the event we wish to avoid direct communication with DM, we may choose other techniques to rank various alternatives. In fact, there are growing interests among practitioners for adapting methods for decision making processes, which rely on both financial and non-financial figures (Kaplan \& Norton, 1992; Kaplan, \& Norton, 1996).

TOPSIS, originally developed by Hwang and Yoon in 1981, is a simple but sophisticated ranking methodology used in many real-world applications of science and engineering (Chang et al., 2010). The standard TOPSIS method chooses alternatives, which simultaneously have the shortest distance from the positive ideal solutions and the longest distance from the negative-ideal solutions. The positive ideal solution maximizes the desirable criteria and minimizes the undesirable criteria, whereas the negative ideal solution maximizes the undesirable criteria and minimizes the desirable criteria. TOPSIS makes full implementation of attribute information, provides a cardinal ranking of 
alternatives, and does not need attribute preferences to be independent. To apply this technique, attribute values must be numeric, monotonically increasing or decreasing, and have commensurable units (Chen and Hwang, 1992; Yoon \& Hwang, 1995).

There are literally different applications of TOPSIS used in many areas of scientific societies and there are various extensions of TOPSIS such as fuzzy TOPSIS. In Fuzzy TOPSIS, we consider uncertainty with input parameters. This extension makes the implementation more realistic since in today's world, uncertainty is an unavoidable part of events and incidents. Aiello et al. (2009), for instance, used fuzzy TOPSIS for clean agent selection.

Amiri (2010) presented project selection for oil-fields development by using the AHP and fuzzy TOPSIS methods. Athanasopoulos et al. (2009) proposed a decision support system for coating selection based on fuzzy logic and multi-criteria decision making. Awasthi et al. (2011a) used an application of fuzzy TOPSIS in evaluating sustainable transportation systems. Awasthi et al. (2011b), in an another assignment, proposed a hybrid approach based on SERVQUAL and fuzzy TOPSIS for evaluating transportation service quality. Performance measurement is another area of implementation of TOPSIS and its extentions such as fuzzy TOPSIS.

Aydogan (2011), for instance, presented an empirical study for performance measurement model for Turkish aviation firms using the rough-AHP and TOPSIS methods under fuzzy environment. Chamodrakas et al. (2009) performed another empirical investigation for customer evaluation for order acceptance using a novel class of fuzzy methods based on TOPSIS. Kelemenis et al. (2011) presented a method for support managers' selection using an extension of fuzzy TOPSIS. Sun and

Lin (2009) used fuzzy TOPSIS method for evaluating the competitive advantages of shopping websites. Krohling and Campanharo (2011) implemented fuzzy TOPSIS for group decision making in a case study for accidents with oil spill in the sea. Thomaidis et al. (2008) used the implementation of TOPSIS for the wholesale natural gas market prospects in the energy community treaty countries.

The proposed study of this paper first uses engineering economy analysis including internal rate of return to investigate whether it is beneficial for the government of Iran to establish gas unit in small town near the city of Qom, Iran. We also present the implementation of multi criteria decision making method to rank ten towns near the city of Qom, Iran. The organization of this paper first presents details of the implementation in section 2 and section 3 presents the results of our survey. Finally, concluding remarks are given in the last to summarize the contribution of the paper.

\section{The proposed model}

In this section, we first present internal rate of return (IRR) to find out whether the establishment of a gas production unit in small town is economically justifiable or not. In our survey, we have realized 28.5 million dollar for pipeline establishment in a small town near the city of Qom. The houses in this town are mainly old and they are not energy efficient. In order to find out how much gas and electricity are required for a typical central heating system, we have used the information of equipments used in city of Tehran during the winter season in 2011.

Based on the results of our survey, in average, the city consumes $3 \mathrm{KW} / \mathrm{m}^{2}$ electricity per six months and $33 \mathrm{~m}^{3}$ gas for each square meter. In our calculation, we have considered 7 cents for KW electricity consumption and considered different rates for gas price. Table 1 shows IRR for under different scenarios.

As we can observe from the results of Table 1, gas distribution is not financially economic when the minimum acceptable rate of return is $25 \%$. The reason is because of the huge amount of investment for pipeline establishment for this town, which is located far from major pipelines and cities. 
Therefore, we need to consider alternative energy replacement for these towns. However, we need to prioritize the cities in terms of different criteria for new sources of energy establishment.

\section{Table 1}

Internal rate of return under different scenarios

\begin{tabular}{cccc}
\hline Gas price & 2000 households & 1500 households & 1000 households \\
\hline 6 & 2 & 2 & 2 \\
8 & 4 & 3 & 2 \\
10 & 5 & 4 & 3 \\
12 & 6 & 5 & 4 \\
14 & 7 & 6 & 4 \\
16 & 8 & 7 & 5 \\
18 & 9 & 8 & 6 \\
20 & 10 & 8 & 6 \\
22 & 11 & 9 & 7 \\
24 & 12 & 10 & 7 \\
26 & 13 & 11 & 8 \\
28 & 14 & 11 & 8 \\
30 & 15 & 12 & 9 \\
32 & 16 & 13 & 9 \\
34 & 17 & 14 & 10 \\
\hline 36 & 18 & 14 & 10 \\
\hline
\end{tabular}

\section{TOPSIS method}

In this section, we first present details of our implementation of TOPSIS method. Let $x_{i j}$ be the inputs for matrix of priorities where there are $i=1, \cdots, m$ alternatives and $j=1, \cdots, n$ criteria. There are six steps associated with the implementation of TOPSIS as follows,

Step 1. Construct normalized decision matrix

$$
r_{i j}=\frac{x_{i j}}{\sqrt{\sum_{i=1}^{m} \sum_{j=1}^{n} x_{i j}^{2}}}
$$

Step 2. Construct the weight normalized matrix

$$
v_{i j}=w_{i} r_{i j}, i=1, \cdots, m \quad j=1, \cdots, n
$$

Step 3. Determin the positive and negative ideal solutions

$$
\begin{aligned}
& A^{+}=\left\{v_{1}^{+}, \cdots, v_{n}^{+}\right\}, \text {where } v_{j}^{+}=\left\{\max \left(v_{i j}\right) \text { if } j \in J ; \min \left(v_{i j}\right) \text { if } j \in J^{\prime}\right\} \\
& A^{-}=\left\{v_{1}^{-}, \cdots, v_{n}^{-}\right\}, \text {where } v_{j}^{*}=\left\{\min \left(v_{i j}\right) \text { if } j \in J ; \max \left(v_{i j}\right) \text { if } j \in J^{\prime}\right\}
\end{aligned}
$$

Step 4. Calculate seperation (positive and negative) measures for each alternative

$$
S_{i}^{+}=\sqrt{\sum_{\mathrm{j}=1}^{\mathrm{n}}\left(v_{j}^{+}-v_{i j}\right)^{2}}, S_{i}^{-}=\sqrt{\sum_{\mathrm{j}=1}^{\mathrm{n}}\left(v_{j}^{-}-v_{i j}\right)^{2}}, i=1, \cdots, m
$$

Step 5. Calculate the relative closness to the ideal solution

$$
C_{i}^{+}=\frac{S_{i}^{-}}{S_{i}^{-}+S_{i}^{+}}, 0<C_{i}^{+}<1, i=1, \cdots, m
$$

We have implemented TOPSIS method for ten towns located in Qom privince. We have considered two criteria of direct sun light radiation and the average temprature during the winter season. We have asked expert to determine the relative importance of each criteria and they mentioned equal rates of importance for both criteria. Table 2 shows details of the implementation of TOPSIS method. 
As we can observe, Esfeed comes as the first priority followed by Moshakieh, Banaber and Ghahan and Nevis. The other five towns are located in the secondary priority due to lower average temperature as well as sun light radiation.

Table 2

Ranking different towns based on the implementation of TOPSIS

\begin{tabular}{ccccc}
\hline City & Average sun light radiation & Average temperature & C & Rank \\
\hline Esfeed & 3.686667 & 6.833333 & 0.9895 & 1 \\
Moshakieh & 3.69 & 6.066667 & 0.8173 & 2 \\
Banaber & 3.683333 & 6.066667 & 0.8172 & 3 \\
Ghahan & 3.613333 & 5.366667 & 0.6497 & 4 \\
Vesfonahrd & 3.696667 & 5.033333 & 0.5717 & 5 \\
Nevis & 3.683333 & 4.766667 & 0.5081 & 6 \\
Kasva & 3.693333 & 3.8 & 0.2786 & 7 \\
Anhalieh & 3.72 & 3.466667 & 0.2007 & 8 \\
Venan & 3.7 & 3.3 & 0.1607 & 9 \\
Kahandan & 3.7 & 2.633333 & 0.0268 & 10 \\
\hline
\end{tabular}

\section{Conclusion}

We have presented an empirical study to measure the relative importance of developing new sources of energy. Despite the fact that Iran is one of the biggest countries in the world in terms of natural gas resources, the country needs to use this source of energy to build value added products. In this paper, we have calculated internal rate of return for estabilishment of gas distribution project in small town located in city of Qom, Iran. Based on the survey we have conducted, we can conclude that gas distribution is not economical for small towns. Therefore, we have presented the implementation of TOPSIS to rank ten different towns located in province of Qom, Iran.

\section{Acknowlegment}

This paper was financially supported by Iranian Gas Distribution Company, Qom branch and the auhtors would like to thank them for their support.

\section{References}

Aiello, G., Enea, M., Galante, G., \& La Scalia, G. (2009). Clean agent selection approached by fuzzy TOPSIS decision-making method. Fire Technology, 45, 405-418.

Amiri, M. P. (2010). Project selection for oil-fields development by using the AHP and fuzzy TOPSIS methods. Expert Systems with Applications, 37, 6218-6224.

Andersen, P., \& Petersen, N. C. (1993). A procedure for ranking efficient units in data envelopment analysis, Management Science, 39, 1261-1264.

Astolfi, M., Xodo, L., Romano, M.C., \& Macchi, E. (2011). Technical and economical analysis of a solar-geothermal hybrid plant based on an organic rankine cycle, Geothermics, 40(1), 58-68.

Athanasopoulos, G., Riba, C. R., \& Athanasopoulou, C. (2009). A decision support system for coating selection based on fuzzy logic and multi-criteria decision making. Expert Systems with Applications, 36, 10848-10853.

Awasthi, A., Chauhan, S. S., \& Omrani, H. (2011a). Application of fuzzy TOPSIS in evaluating sustainable transportation systems. Expert Systems with Applications, 38, 12270-12280.

Awasthi, A., Chauhan, S. S., Omrani, H., \& Panahi, A. (2011b). A hybrid approach based on SERVQUAL and fuzzy TOPSIS for evaluating transportation service quality. Computers \& Industrial Engineering, 61, 637-646. 
Aydogan, E. K. (2011). Performance measurement model for Turkish aviation firms using the roughAHP and TOPSIS methods under fuzzy environment. Expert Systems with Applications, 38, 3992-3998.

Charnes A, Cooper, W. W., Rhodes, E. (1978). Measuring the efficiency of decision making units. European Journal of the Operational Research, 2, 429-44.

Charnes A, Cooper W. W., Lewin, A., Seiford, L. M. (1994). Data envelopment analysis: theory, methodology and applications. Massachusetts: Kluwer Academic Publishers.

Chen, S. J., \& Hwang, C. L. (1992). Fuzzy multiple attribute decision making: Methods and applications. Berlin: Springer-Verlag.

Chang, C. H., Lin, J. J., Lin, J. H., \& Chiang, M. C. (2010). Domestic open-end equity mutual fund performance evaluation using extended TOPSIS method with different distance approaches. Expert Systems with Applications, 37, 4642-4649.

Chamodrakas, I., Alexopoulou, N., \& Martakos, D. (2009). Customer evaluation for order acceptance using a novel class of fuzzy methods based on TOPSIS. Expert Systems with Applications, 36, 7409-7415.

Fridleifsson, I. B. (2001). Geothermal energy for the benefit of the people. Renewable and Sustainable Energy Reviews, 5(3), 299-312.

Imroz Sohel, M., Sellier, M., rackney, L.J., \& Krumdieck, S. (2009). Efficiency improvement for geothermal power generation to meet summer peak demand. Energy Policy, 37(9), 3370-3376.

Murphy, H., \& Niitsuma, H. (1999). Strategies for compensating for higher costs of geothermal electricity with environmental benefits. Geothermics, 28(6), 693-711.

Nannen, L.W., Kreith, F., \& West, R.E.(1976). An investigation of the technical and economical feasibility of using low temperature geothermal sources in Colorado. Energy, 1(2), 179-216.

Kaplan, R. S. \& Norton, D. P. (1992). The balanced scorecard - measures that drive performance, Harvard Business Review, 70(1), 71-79.

Kaplan, R.S. \& Norton, D.P. (1996). The balanced scorecard: translating strategy into action, Harvard Business School Press, Boston, MA.

Kaygusuz, K., \& Kaygusuz, A. (2004). Geothermal energy in Turkey: the sustainable future. Renewable and Sustainable Energy Reviews, 8(6), 545-563.

Kanoglu, M., Bolatturk, A. (2008). Performance and parametric investigation of a binary geothermal power plant by exergy. Renewable Energy, 33(11), 2366-2374.

Kelemenis, A., Ergazakis, K., \& Askounis, D. (2011). Support managers' selection using an extension of fuzzy TOPSIS. Expert Systems with Applications, 38, 2774-2782.

Kose, R. (2007). Geothermal energy potential for power generation in Turkey: A case study in Simav, Kutahya. Renewable and Sustainable Energy Reviews, 11(3), 497-511.

Krohling, R. A., \& Campanharo, V. C. (2011). Fuzzy TOPSIS for group decision making: A case study for accidents with oil spill in the sea. Expert Systems with Applications, 38, 4190-4197.

Rodríguez, R., \& Díaz, M.B. (2009). Analysis of the utilization of mine galleries as geothermal heat exchangers by means a semi-empirical prediction method. Renewable Energy, 34(7), 1716-1725.

Saaty, T. L. (1992). How to make a decision: the analytic hierarchy process. European Journal of Operational Research, 48, 9-26.

Sun, C. C., \& Lin, G. T. R. (2009). Using fuzzy TOPSIS method for evaluating the competitive advantages of shopping websites. Expert Systems with Applications, 36, 11764-11771.

Vélez, F., Segovia, J.J., Martín, M.C., Antolín, G., Chejne, F., \& Quijano, A. (2012).A technical, economical and market review of organic Rankine cycles for the conversion of low-grade heat for power generation. Renewable and Sustainable Energy Reviews, 16(6), 4175-4189.

Thomaidis, F., Konidari, P., \& Mavrakis, D. (2008). The wholesale natural gas market prospects in the energy community treaty countries. Operational Research International Journal, 8, 63-75.

Yoon, K. P., \& Hwang, C. L. (1995). Multiple attribute decision making. Thousand Oaks, CA: Sage Publication.

Yildirim Ozcan, N., \& Gokcen, G. (2009). Thermodynamic assessment of gas removal systems for single-flash geothermal power plants. Applied Thermal Engineering, 29(14-15), 3246-3253. 